\title{
Development of College Newspaper Management System Based on Mobile Devices
}

\author{
Yuyou He, Tiejun Feng
}

Computer Science, Zaozhuang Vocational College of Science Technology, Teng Zhou, 277500 China.

\begin{abstract}
In order to adapt to the huge impact and influence brought by the mobile networks as well as the Internet to the university newspaper, it is imperative to implement an intelligent, digitalized school newspaper management system. Based on mobile devices, the hierarchical structure of the program was designed according to the MVC framework in ASP.NET development on the basis of mobile devices, and the process design of the operation business was carried out respectively for the user end, the front end, the school newspaper editorial management system, and the website background management system, so that the scientific management of the university was realized. In addition, all-around information collection, highspeed processing, high-density storage and long-distance transmission were realized by the users, which enabled people to search for the required information in a comprehensive, fast, and accurate manner. Thus, the information resources could be developed and used more effectively. The results showed that the design and development of college newspaper management system could bring convenience to users and schools.
\end{abstract}

Key words: Mobile Phone Network; Intelligentization; Digitization; Mobile Equipment; Information-Based Management.

\section{INTRODUCTION}

With the development of computer technology and the advent of the Internet era, mobile devices are rapidly gaining popularity due to their advantages of small size, light weight, and low energy consumption. Applications based on mobile networks are becoming more and more popular and playing an important role in people's daily lives and work [1]. The popularization of technology applications such as information networks and automation controls make intelligentization a social development trend. Human beings have entered the digital age and new technologies are constantly being introduced into the field of education. Also, the media in colleges and universities is developing rapidly [2]. As one of the leading media in colleges and universities, university newspaper, as an important tool for ideological propaganda on campus, plays an important role in promoting the teaching, scientific research and discipline construction of colleges and universities. Under the digital environment, college newspapers are facing the impact from the campus network and online media, so how to adapt to the situation and effectively use new technologies is a major issue for college newspapers [3]. The digitalization of university newspapers is an inevitable choice to adapt to the development of the times, and it is an important way to use new technologies in saving funds and attracting teachers and students.

Based on what has been discussed above, a school newspaper management system is designed and developed with the help of the ASP technology and Access2003 database technology on the basis of the analysis of the related theories of the school newspaper management system in order to improve the existing school newspaper management system and provide reference for the use of new technology in the development of the university newspaper. 


\section{TECHNOLOGY RELATED TO COLLEGE NEWSPAPER SYSTEM \\ The MVC Framework Mode}

The MVC is a framework mode that decomposes an application into three parts: Model, View, and Controller (Controller). Each part is responsible for its own function, and the modules are relatively independent.

In the MVC framework mode, views are the interface between the user and the program [4]. In Web development, views are usually composed of HTML, XML, and other mark-up languages.

The structure of the MVC framework is shown in Figure 1.

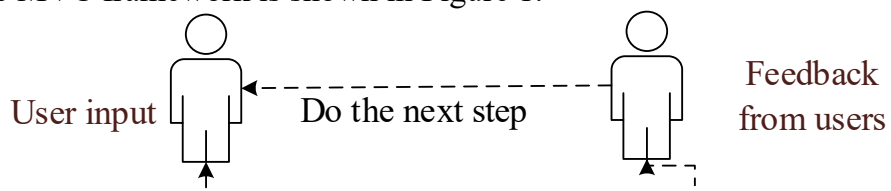

human-qomputer interaction human-computer interaction

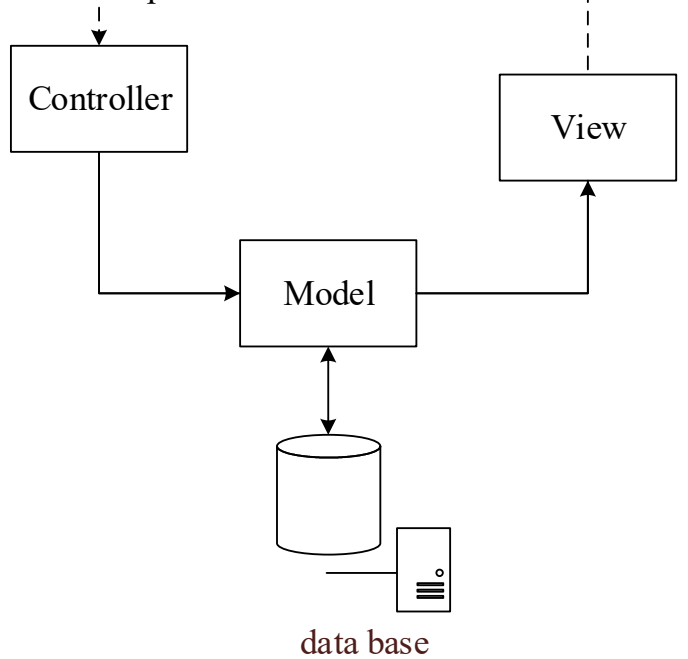

FIGURE 1. The MVC architecture of ASP.NET.

\section{Analysis of the ASP.NET MVC Program Structure}

An application based on the ASP.NET MVC framework can be divided into the following parts: Reference, Content, Views, Models, Controllers, Default.aspx, and Global. Sax, and the configuration file Web.config. Among them, Web.config configures web site information of the web program, and Global. Sax deploys web application routing information [5]. Default.aspx is the default page, which is also the home page of the website.

In the reference assembly, compared with ordinary ASP.NET programs, there are additional ASP.NET MVC assembly packages, which are also the packages implemented by MVC's main function. The basic classes and interfaces of the MVC are added to the assembly Web. Abstractions. In the cubbyhole Content, the CSS style design files needed for the web pages are included, as well as some JavaScript files controlled by the interface. In the folder Views, user interactive view interface is stored, which is the Asp program. The shared folder can store the template page.ascx program designed for the overall style of the website. In the folder Models, the basic data model is stored.

\section{DEMAND ANALYSIS OF THE SCHOOL NEWSPAPER MANAGEMENT SYSTEM}

The main functions of the school newspaper management system are background management and front-end display. The front-end displays major secondary navigation, the layout navigation, the article navigation, and school newspaper information, etc. The school newspaper information includes the school newspaper's header information, publishing units, organizers, competent authorities, authoritative email address, contact ways, etc. [6]. The 
background management interface provides the following functions: the school newspaper information management, the layout management, the school newspaper publication management and the article management.

The main function of the school newspaper information management is to create new newspapers and magazines and to conduct the operations such as modification and deletion of information;

The main function of the layout management is to view, delete and modify the existing layouts, add new layout information as well as view, modify, and delete the layout information;

The school newspaper publication management: This function is mainly to determine whether the school newspaper in the system is to be published or not and to manage the published as well as the unpublished school newspapers;

The main function of the article management is to review, modify, and cascade to manage related newspapers and accessory information of the school newspaper;

The school newspaper is cascaded to the layout management to carry out the layout management, the layout information management and other functions of the school newspaper.

\section{The System Design}

The school newspaper management system uses the ASP (Active Server Pages) network programming technology by taking Access 2003 as the back-end database and using B/S mode to complete the development of the entire system. The system is a full-featured web application that is mainly composed of three main parts: reader browsing, information management and background management.

The reader's browsing module: It is also the front-page window used for browsing of the content of the school newspaper and the PDF version download.

The reader becomes a registered member after registration and login. The functions of the reader's client include: browsing news, commenting on news, rating of news, and comments of readers [7].

Basic path:

The reader enters the login screen and enters a username and a password.

The reader clicks on the "Login" button.

The reader reads the news. (The reader comments on the news, rates and evaluates the quality of the news. He can also leave massages to the editorial department) [8].

The readers submit their own content and click on the "Submit" button.

The system displays the "submit successfully" prompt.

Administrator management module: the administrator page window is mainly used for addition, deletion, and modification of the user' information. The administrator module settings login window of the school newspaper management: Only when the correct user name and password are entered can one enter the related background pages to operate. In order to standardize the management of digital school newspapers and strictly control quality, the system adopts a two-fold management mechanism. The administrator authority is set to general administrators and senior administrators. The general administrator is responsible for editing and uploading journal information and news while the senior administrator is responsible for the review and release of information. In addition, the administrator's password is also encrypted in consideration of system management security.

Information management module: The information management page window is mainly used for the addition, deletion and modification of school newspaper information; it's also used for the addition, deletion and modification of the layout information as well as the addition, deletion and modification of news; the uploading of PDF version of the school newspaper is also its function. 


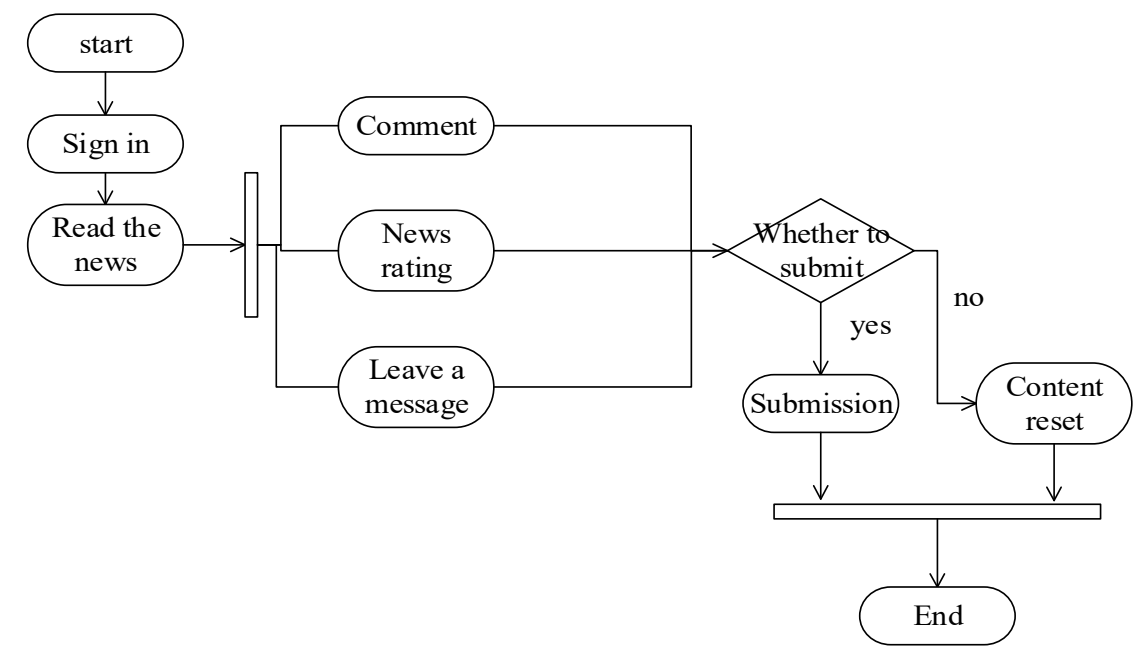

FIGURE 2. "Reader Role Operation" activity diagram.

The Functional Structure Diagram of the System

According to the demand analysis of the school newspaper management system above, the overall functional structure of the system is determined, as shown in Figure 3.

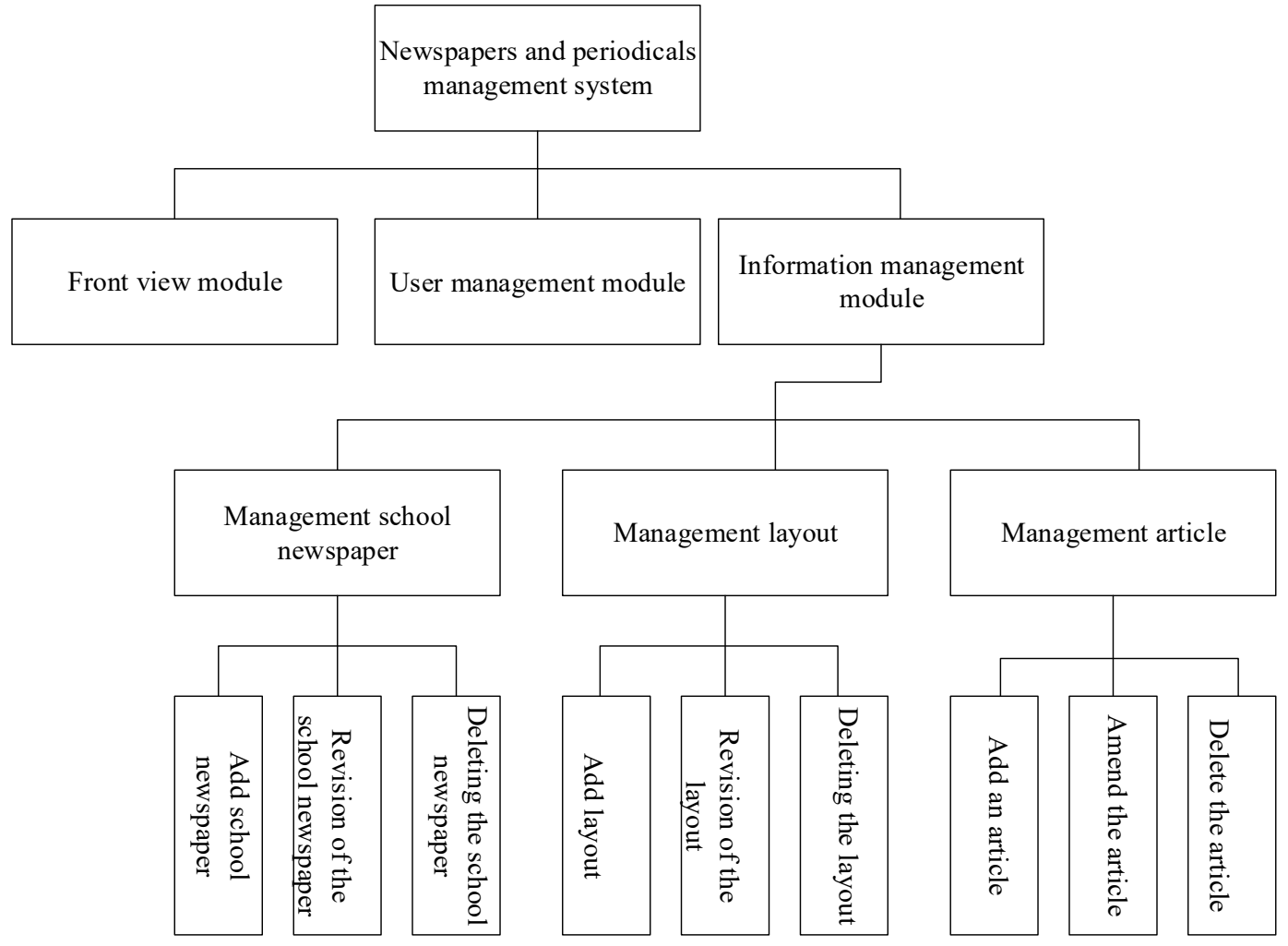

FIGURE. 3. The System function structure. 


\section{THE DETAILED DESIGN AND IMPLEMENTATION OF VARIOUS FUNCTIONAL MODULES OF THE SCHOOL NEWSPAPER MANAGEMENT SYSTEM}

\section{The Architecture Design of the School Newspaper Information Management System}

The reader and reporter client architecture design:

According to the basic idea of the MVC architecture model as well as the specifications of the needs of the reader and reporter client functions, the structure of the Android client is divided into four layers: the user interface layer, the boundary control layer, the business processing layer, and the model physical layer.

The editorial management and website management system architecture design:

The architecture of the editorial management system and website management system is designed into four levels: the view interface layer, the boundary control layer, the business processing layer, and the database.

\section{Data Model Design}

The data conceptual model design:

The concept of role categories: There are four user roles, namely, readers, reporters, editors, and system administrators.

The concept of object class: news, rank, and messages.

Operational concepts: comments, ratings, and auditing.

The data sheet design:

TABLE 1. The readers' information table.

\begin{tabular}{|c|c|c|c|}
\hline Section Name & Field meaning & Type & Instructions \\
\hline Reader Name & Reader's name & Archer & \\
\hline Reader PW & Reader's password & Archer & \\
\hline Reader Phone & Reader's phone number & Number & \\
\hline Reader Numb & Reader's ID & Archer & Pike \\
\hline
\end{tabular}

The Implementation of the Database and the Reader Client.

The editorial management system and the website background management system of the school newspaper information management system use ADO.NET components to achieve data access. The method used is to access the data by combining the data set Data Set and the data adapter Data Adapter. In the reader client system, a total of seven user interfaces are implemented: the reader registration interface, the reader client login interface, the system master interface of the reader client, the reader client news reading interface, the reader's news review interface, the reader news rating interface, and the reader's message interface.

\section{The Implementation of the Editorial Information Management Module}

The editorial management system is divided into four layers: the user interface layer, the boundary control layer, the business processing layer, and the database layer.

The user interface layer: The editing management system interface is implemented through the editing management main interface, the news review interface, the comment management interface, the message management interface, and the news rating management interface.

The boundary control layer: The implementation of the boundaries of the editorial management system is through the editorial management boundary, the news review boundary, the comment management boundary, the message management boundary, and the news rating management boundary.

The business processing layer: The business processing layer is the data set News Data Set.

Database: including the system database Data Base and the tables under the database.

Therefore, in the editorial management system, five user interfaces are realized: the editing management main interface, the news auditing interface, the review management interface, the message management interface, and the news rating management interface. 


\section{CONCLUSION}

To get out of the predicament, it is necessary for the college newspapers to work hard on the integration of newspapers and networks. The school newspaper management system is a product of the school newspaper's new media environment. It can not only adapt to the development of the times and attract more readers but also save money to a certain extent, attract readers, and continue to influence teachers and students. This thesis describes the school newspaper management system by using technologies such as the ASP technology and Access database with characteristics of simple operation and maintainability. The technology is developing at a high speed, so how to use new technologies to better promote the development of college newspapers and adapt to the new situation is worth everyone's attention.

\section{REFERENCES}

1. Lorenz R D, Blame M R, GU Z, et al. History and Applications of Dust Devil Studies. Space Science Reviews, 2016, 203(1-4), pp. 1-33.

2. Podolsk E A, Izumi K, Suchow V E, et al. Physical and societal statistics for a century of snow-avalanche hazards on Sakhalin and the Kuril Islands (1910-2010). Journal of Glaciology, 2017, 60(221), pp. 409-430.

3. Woods L. Neuse H.S. among Top in Nation; Newsweek Ranks School in Top 4\%. Food Chemistry, 2016, 199, pp. 439-446.

4. Langford B N. Printers Take to the Cloud: As the Magazine Industry Changes, One of Its Core Supplier Categories, Printing, and Morphs from Old-School Owner of Big Iron to Multi-Faceted Technology Provider. One of the Hottest Areas of Growth Is in the Application-Service Pro. Nanotechnology, 2011, 22(47), pp. 1029-1032.

5. Hilton S, Patterson C, Ceyhan A. Escalating Coverage of Obesity in UK Newspapers: The Evolution and Framing of the "Obesity Epidemic" From 1996 to 2010. Obesity, 2012, 20(8), pp. 1688-1695.

6. Bark M. Maintenance N-acetyl cysteine treatment for bipolar disorder: A double-blind randomized placebocontrolled trial. Bum Medicine, 2012, 10(1), pp.91.

7. Stepzinski T. Pair of Contested Primary Races on Ballot for Glynn School Board. Caries Research, 2013, 47(4), pp. 273-83.

8. Clark S G, Vernon M E. Governance Challenges in Joint Inter-Jurisdictional Management: The Grand Teton National Park, Wyoming, Elk Case. Environmental Management, 2015, 56(2), pp. 286-299. 